\title{
Pressupostos da pesquisa e da formação continuada de historiadores docentes: uma contribuição da Educação Histórica
}

\author{
Research and history teacher continuing education assumptions: a \\ History Education contribution
}

\section{Suposiciones de investigación y educación continua de profesores de historia: una contribución de la Educación Histórica}

\author{
Thiago Augusto Divardim de Oliveira' \\ Instituto Federal do Paraná, Professor. \\ https://orcid.org/0000-0003-4719-5565
}

Resumo: 0 artigo apresenta possibilidades de sistematização de pressupostos relacionados aos trabalhos desenvolvidos no âmbito do Laboratório de Pesquisa em Educação Histórica da Universidade Federal do Paraná (LAPEDUH - UFPR) no que diz respeito aos cursos de extensão voltados à formação continuada de professores de História das redes públicas de ensino (municipal e estadual). 0 tema central da análise está relacionado a um projeto experimental realizado em parceria entre o LAPEDUH - UFPR, o Instituto Federal do Paraná (Campus Curitiba) e a Secretaria Municipal de Educação de Curitiba, que resultou na produção de três vídeos relacionados aos temas dos cursos realizados em 2017 e 2018: "Educação Histórica e Temas Controversos da História". A produção dos vídeos envolveu dois projetos de pesquisa e extensão do IFPR (das áreas: "Didática da História" e "Produção de Áudio e Vídeo"), e os produtos são voltados para professores interessados em temas do campo da Educação Histórica, resultando em um material paradidático produzido por professores para professores. 0 procedimento metodológico utilizado foi análise de conteúdo (FRANCO, 2007) dos vídeos a partir de um diálogo com as teorias da história que embasaram o curso e embasam as produções no âmbito do Laboratório. Entre os resultados apontamos a produção dos vídeos como divulgação do trabalho de historiadores docentes, as produções bibliográficas relacionadas ao curso de extensão; o diálogo entre a teoria e a práxis nas enunciações dos professores; e, ainda, a incorporação de elementos teóricos, metodológicos e estratégias didáticas discutidas em colaboração ao longo do curso.

Palavras-chave: Educação Histórica. Formação de professores. Práxis.

Mestre e Doutor em Educação na linha Cultura, Escola, Ensino pela Universidade Federal do Paraná. 
Abstract: The article presents systematization possibilities of assumptions related to the work developed within the History Education Research Laboratory of the Paranás Federal University (LAPEDUH - UFPR), regarding Extension courses aimed at the continuing education of public schools History teachers (from municipal and state schools). The central theme of the analysis is related to an experimental project carried out in partnership between LAPEDUH - UFPR, the Federal Institute of Paraná (Curitiba Campus) and the Curitiba Municipal Education Secretary, which resulted in the production of three videos related to the subjects of the courses held in 2017 and 2018: "History Education and History Controverse Topics". The production of the videos involved two IFPR research and extension projects (from the areas: "History Didactics" and "Audio and Video Production") and the products are aimed at teachers interested in subjects in the field of History Education, resulting in a paradidatic material produced by teachers to teachers. Among the results we point out the production of the videos as dissemination of the work of history teachers, the bibliographic productions related to the extension course; the dialogue between theory and praxis in teachers' statements; and the incorporation of theoretical, methodological and didactic strategies discussed in collaboration throughout the course.

Keywords: History Education. Teacher training. Praxis.

Resumen: El artículo presenta las posibilidades de sistematización de suposiciones relacionadas a los trabajos desarollados en el ambito del Laboratório de Pesquisa em Educação Histórica da Universidade Federal do Paraná (LAPEDUH - UFPR) al respecto de los cursos de Extensión guiados a la formación continuada de los maestros de Historia de las redes publicas de enseño (municipal y estadual). El tema central del analisis esta relacionado a un proyecto experimental realizado en sociedad entre el LAPEDUH - UFPR, el Instituto Federal de Paraná (Campus Curitiba) y la Secretaria Municipal de Educación de Curitiba que resultó en la producción de tres videos relacionados a los temas de los cursos realizados en el año de 2017 y 2018: "Educación Histórica y Temas Controvertidos de la Historia". La producción de los videos envolvió dos proyectos de investigación y extensión del IFPR (de las áreas: "Didáctica de la História" y "Producción de audio y video") y los productos se vuelcan a los profesores interesados en el tema del campo de la Educación Histórica resultando en un material paradidatico producido por maestros para maestros. El procedimiento metodologico utilizado fue el analisis del contenido (FRANCO, 2007) de los videos a partir de un dialogo con las teorias de la historia que basaron el curso y las producciones en el laboratorio. Entre los resultados destacamos la producción de los videos como divulgación del trabajo de los historiadores docentes, las producciones bibliográficas relacionadas al curso de extención; el dialogo entre la teoria y la practica en las enunciaciones de los maestros; $y$, todavia, la incorporación de los elementos teóricos, metodologicos y estrategias didacticas discutidas en colaboración a lo largo del curso.

Palabras-llave: Educación Histórica. Formación de maestros. Práxis. 


\section{INTRODUÇÃO}

0 Laboratório de Pesquisa em Educação Histórica (LAPEDUH) foi formado em 2003, mas sua organização é decorrente de um acúmulo de trabalhos que foram desenvolvidos no âmbito da linha de Pesquisa "Cultura, Escola e Ensino ${ }^{2 "}$ do Programa de Pós-graduação em Educação da Universidade Federal do Paraná. Desde 1996, trabalhos de pesquisa lque envolveram da iniciação científica à pós-graduação), assim como projetos de extensão desenvolvidos na Universidade - especialmente a formação continuada de professores e professoras de redes municipais, como, por exemplo, no projeto Recriando Histórias - ${ }^{3}$ além de atividades de Ensino - como a disciplina "Educação Histórica” na própria Pós-graduação e que é aberta aos professores de História das redes públicas de ensino -, criaram a necessidade de uma discussão mais relacionada aos processos de ensino e aprendizagem da disciplina de História.

De acordo com informações retiradas do histórico do Laboratório, elementos relacionados à conjuntura internacional e suas implicações no processo formativo dos seres humanos também estão entre os elementos que levaram à sua configuração:

\footnotetext{
A conjuntura do novo século parece acumular várias crises, entre elas a de ruptura com as perspectivas que tradicionalmente se impuseram como modo de interpretar, representar e reproduzir a realidade, frente às reacomodações do capitalismo mundial e suas especificidades nacionais. Neste sentido, tornou-se imperativo problematizar os fundamentos da relação entre sociedade, ciência e educação, constitutivos dos processos de conhecimento, investigação e ensino de História. Em certa medida, isto significa a necessidade de desvelar conceitos epistemológicos que afetam a teoria e a prática do ensino de História, tendo como referência o saber histórico e educacional, bem como o estabelecimento de um rigoroso diálogo entre a investigação científica da História e sua correspondente investigação didática. (LABORATÓRIO DE PESQUISA EM EDUCAÇÃO HISTÓRICA - UFPR, [20--]).
}

Entre 2003 e 2019, os projetos foram amadurecendo e ganhando um corpo teórico mais definido em relação às discussões do campo do ensino de história no que se relaciona à teoria da História, suas relações com o ensino e a aprendizagem da História, assim como nos diálogos com outros campos do conhecimento científico, seja da antropologia, da sociologia, da psicologia ou da didática em geral. Com mais de 15 anos de trajetória, é preciso levar

Atualmente chamada "Cultura, Escola e Processos Formativos em Educação".

3 Projetos de extensão que foram desenvolvidos junto a escolas de municípios da região metropolitana de Curitiba, com o intuito de oferecer formação continuada de professores, assim como a produção de materiais didáticos ligados à História local, de pessoas comuns e a partir e fontes em estado de arquivo familiar. 
em consideração a historicidade das produções do Laboratório, assim como seus diálogos e parcerias de produção, ou mesmo a recepção e resignificação de traduções e debates teóricos.

A partir dos 15 anos de existência do Laboratório foi possível realizar algumas produções que atualizam essa trajetória realizada de maneira coletiva e colaborativa entre professores e pesquisadores. Como o Laboratório tem sido composto principalmente por pesquisadores que lecionam História na educação básica e as atividades de pesquisa e ensino muitas vezes estão entrelaçadas, vamos chamar de historiadores docentes as professoras e os professores que participam e participaram dessa trajetória. Entre essas obras de atualização e exame da produção do Laboratório poderíamos citar o livro Educação Histórica - Ousadia e Inovação em Educação e em História (2018), pois se trata de uma obra que reúne produções de pesquisadores e pesquisadoras que servem como referência bibliográfica para as produções do Laboratório, assim como trabalhos resultantes das reflexões de orientandos que passaram pelo Laboratório ou que ainda o compõem.

A motivação e as análises propostas neste texto se dedicam tanto à divulgação dos elementos cientificamente pensados no âmbito do LAPEDUH quanto das perspectivas possíveis na área do ensino de história a partir dos trabalhos realizados por docentes das redes públicas de ensino. Ao mesmo tempo em que realizamos uma análise de elementos fundantes e pressupostos dos trabalhos realizados na área da Educação Histórica e da formação de professores.

\footnotetext{
Na construção da ciência vale o pensamento de Heráclito, de que o caminho para cima e para baixo é o mesmo [...] Quanto mais crescer o edifício da ciência e quanto maior o arrojo, com o qual ele se projeta às alturas, tanto mais ele necessita do exame e da renovação constante dos seus fundamentos. A afluência de novos fatos deve ser correspondida pelo 'rebaixamento dos fundamentos', que caracteriza, segundo Hilbert, a essência de toda e qualquer ciência. Se isto é verdadeiro, fica claro o fato de que e a razão pela qual não podemos aliviar as ciências particulares do trabalho pela identificação e pelo fortalecimento dos princípios nem delegar esta tarefa a uma disciplina "filosófica" especial, à 'teoria do conhecimento' ou à metodologia. (CASSIRER, 1961, p. 17 apud RÜSEN, 1987). ${ }^{4}$
}

Nesse sentido, é possível apontar alguns desses elementos que podemos perceber atualmente a partir de um esforço de exame e reconstrução de elementos centrais

4 Seguindo o exemplo de Rüsen (1987) no texto Reflexões sobre os fundamentos e mudança de paradigma na ciência histórica alemã-ocidental, aproveitamos a epígrafe em que o autor cita Cassirer e sistematizamos muito rapidamente alguns aspectos históricos das produções do LAPEDUH, no sentido de aprofundar alguns pressupostos relacionados à Educação Histórica e à Formação de professores. 
dessa trajetória. Se não são todos os momentos que evidenciam essas características, elas poderão valer como elementos que visam sustentar a continuidade dos trabalhos no Laboratório.

\section{PRESSUPOSTOS DA PESQUISA DE HISTORIADORES DOCENTES E DA SUA FORMAÇÃO CONTINUADA ${ }^{5}$}

Nesta seção apresentamos três pressupostos básicos que não estão hierarquizados em ordem de importância, pois fazem parte de um todo orgânico e estão aqui divididos apenas para auxiliar a percepção e a compreensão daquilo que conforma um total nocional das perspectivas que envolvem os debates e as produções nas áreas da Educação Histórica e formação de professores: pressuposto 1 - A atividade docente como trabalho; pressuposto 2 - A metodologia da pesquisa colaborativa; pressuposto 3 - A compreensão da Teoria da consciência histórica na perspectiva da práxis.

1. Elemento essencial que faz parte dos debates e produções do grupo, trata da compreensão de que professores e professoras são intelectuais, realizam trabalho intelectual e, para a realização efetiva da intelectualidade, precisam de condições materiais objetivas de trabalho, assim como condições para a realização do trabalho intelectual. Para evitar qualquer equívoco de compreensão, recorremos aqui diretamente ao pensamento de Gramsci (1982, p. 7):

Quando se distingue entre intelectuais e não-intelectuais, faz-se referência, na realidade, tão-somente a [sic] imediata função social da categoria profissional dos intelectuais, isto é, leva-se em conta a direção sobre a qual incide o peso maior da atividade profissional específica, se na elaboração intelectual ou se no esforço muscular-nervoso. Isto significa que, se se pode falar de intelectuais, é impossível falar de não-intelectuais, porque não existem não-intelectuais. Mas a própria relação entre o esforço de elaboração intelectual-cerebral e o esforço muscular-nervoso não é sempre igual; por isso, existem graus diversos de atividade específica intelectual. Não existe atividade humana da qual se possa excluir toda intervenção intelectual, não se pode separar o homofaber do homosapiens.

Esse elemento é um pressuposto que possibilita evidenciar a importância da atividade docente assim como a crítica às condições em que muitas vezes essa atividade se realiza. 0 caráter aberto das reuniões do LAPEDUH, por exemplo, sempre às quintas-feiras

Para uma leitura detalhada dos pressupostos ver o texto $A$ didática da história e os trabalhos LAPEDUH: pressupostos da pesquisa de historiadores docentes, de Urban, Martins e Cainelli (2018). 
no período da tarde nas dependências da Universidade Federal do Paraná, possibilita, na medida em que permite a circulação de conhecimentos científicos produzidos na academia, a realização de um trabalho na força de trabalho dos historiadores docentes.

Os cursos de extensão oferecidos em parceria com a Secretaria Municipal de Educação de Curitiba, ou em anos anteriores com a Secretaria de Estado da Educação do Paraná (SEED - PR) criam/criaram condições para a apropriação de meios intelectuais de produção que possibilitam aos docentes a participação em pesquisas, a produção acadêmica, a divulgação dos conhecimentos cientificamente elaborados em eventos nacionais e internacionais, assim como revistas de divulgação científica, de maneira que transformam as condições de exercício da atividade docente. No entanto, o não reconhecimento da produção de professores da educação básica, por exemplo, ao contrário do que ocorre na Educação Superior ou na Educação Básica Técnica e Tecnológica, interfere nas possibilidades le mesmo incentivo) à qualificação docente. ${ }^{6}$

Objetivamente: se não há condições materiais para o desenvolvimento do trabalho intelectual, ou, o que é ainda pior, em tempos de cortes e contingenciamentos na área da educação se limitam-se momentos de hora-atividade e possibilidades de pesquisa, estudo e preparação de aulas (ou seja, condições para a realização do trabalho intelectual), restringese a própria possibilidade de melhoria da educação. A compreensão das relações de trabalho na educação e das possibilidades e limites da realização do trabalho intelectual configuram um dos pressupostos das discussões sobre a formação de professores no âmbito do LAPEDUH.

2. A metodologia da pesquisa colaborativa discutida a partir das produções de lbiapina (2008) e também do acúmulo de trabalhos realizados desde momentos anteriores à criação do LAPEDUH carrega a compreensão de que a relação entre pesquisadores e professores (que também configuram relações de trabalho) caracteriza uma prática social que não deve ser pensada em abstrato, mas como parte das relações de trabalho e condições materiais objetivas, discutidas no primeiro pressuposto, mas, além disso, a pesquisa como uma forma em que historiadores docentes (da universidade e da escola) se dedicam a refletir dialeticamente os problemas que fazem parte da educação, da escola e das relações de ensino e aprendizagem em história, de maneira a tentar intervir para a melhoria de práticas sociais já existentes. 
A prática da pesquisa colaborativa envolve investigadores e professores tanto em processos de produção de conhecimentos quanto de desenvolvimento interativo da própria pesquisa, haja vista que $\circ$ trabalho colaborativo faz com que professores e pesquisadores produzam saberes, compartilhando estratégias que promovem desenvolvimento profissional. Nessa perspectiva, é atividade de co-produção de conhecimentos e de formação em que os pares colaboram entre si com o objetivo de resolver conjuntamente problemas que afligem a educação. (IBIAPINA, 2008, p. 25).

A pesquisa colaborativa como pressuposto metodológico cria condições para que professores e pesquisadores ampliem a compreensão das realidades pesquisadas a partir de um diálogo interessante para o professor e para o pesquisador, e nesse caso é comum que as figuras envolvidas exerçam as duas funções, mesmo que em graus de inserção diferenciados. A produção dos vídeos que serão analisados adiante, ou os textos publicados por professores que participam dos cursos, são indicativos dessa ampliação mútua da compreensão das realidades pesquisadas.

3. Complementando os dois pressupostos anteriores, é possível apresentar alguns elementos característicos das discussões teóricas realizadas no LAPEDUH. Em mais de 15 anos de trajetória há, positivamente, mudanças nas formas de compreensão e diálogo com determinadas teorias. Os diálogos iniciais, por exemplo, com as produções portuguesa e inglesa do campo da Educação Histórica foram marcados por elementos da teoria da história que se fundamentavam na filosofia analítica e em teorias da mudança conceitual. De maneira quase concomitante ocorreram apropriações e diálogos com a teoria da consciência histórica proposta por Rüsen (2001). Com a ampliação das publicações, traduções e pesquisas que dialogaram com essas referências foram se estabelecendo aspectos da compreensão, e mesmo do diálogo, com essas teorias que hoje conformam características próprias da produção no Laboratório.

Valorizamos em diálogo com os pressupostos já discutidos o processo de produção da consciência histórica discutida por Rüsen com base na ldeologia Alemã de Marx e Engels (2007). Para haver consciência histórica, é necessário que haja a satisfação das carências estruturais da vida humana. A satisfação das primeiras carências (de comida, bebida, moradia, vestimenta e algumas coisas mais) leva à produção de novas carências, a satisfação desses elementos é um elemento que se dá (e sempre se deu) de maneira social e coletiva, portanto apenas com esses três estágios é possível chegar ao pressuposto da consciência histórica propriamente dita. Satisfação de si, relação consigo e com os outros, reprodução da vida, de um lado como relação natural, de outro como relação social, sejam quais forem o modo, as condições e finalidades. A consciência, consequentemente, não surge ou passa por um processo de formação puro ou abstrato. 
Isso pode ser demonstrado na estrutura de carências humanas, tanto interna quanto externa. Diversamente dos animais, o homem desenvolve qualitativamente, a partir da satisfação de suas carências, novas carências. Não há como estabelecer um critério que permita classificar as carências entre "naturais" e "artificiais" e, com isso, problematizá-las. A inquietude temporal especificamente humana é ínsita à natureza faustiana do homem: "Que vida! angústias sempre: ora a almejar por gozo, ora inquieto na posse, e do almejar saudoso!" (RÜSEN, 2015, p. १20, grifo do autor).

Em seguida, o autor apresenta uma nota de rodapé que é muito significativa para as discussões a respeito da compreensão das relações de ensino e aprendizagem em história, assim como do próprio processo de formação de professores:

A quem isso soe demasiado poético, remeta-se à antropologia histórica de Karl Marx, tal como a expôs no capitulo sobre Feuerbach na "Ideologia Alemã". Marx chama a atenção que a primeira carência satisfeita lde assegurar materialmente a vida, J.R.J, "a ação de satisfazer e o instrumento mesmo da satisfação conduzem a novas carências - e essa produção de novas carências é a primeira ação histórica". (RÜSEN, 2015, p. 122, grifo nosso).

A partir dessa compreensão fundamental, tem sido possível defender elementos de uma Educação Histórica (como parte das discussões do campo da Didática da História) que se referencia em elementos da práxis, que estabelece diálogos com referências essenciais para pensar a Educação no Brasil, a exemplo de Paulo Freire (SCHMIDT, 2006, 2012), assim como elementos do próprio materialismo histórico:

\begin{abstract}
Será que a aprendizagem conduz à auto-realização dos individuos como "indivíduos socialmente ricos" humanamente, ou ela está a serviço da perpetuação, consciente ou não, da ordem social alienante e definitivamente incontrolável do capitale. Este autor afirma, ainda, que "os processos educacionais e os processos sociais mais abrangentes de reprodução estão intimamente ligados, e uma reformulação significativa da educação é inconcebível sem a correspondente transformação do quadro social no qual as práticas educacionais da sociedade devem cumprir as suas vitais e historicamente importantes funções de mudança. (MÉSZAROS, 2007, p. 196 apud SCHMIDT, 2014, p. 109).
\end{abstract}

Quando relacionamos o conceito de consciência histórica e sua relação dialética com o complexo mais amplo da cultura histórica, não estamos analisando, por exemplo, explicações de estudantes a respeito de determinado conteúdo escolarizado, mas buscamos perceber a narrativa como expressão da consciência, que passa por processos formativos em condições materiais que possuem suas especificidades (culturais, econômicas, estéticas, 
éticas, morais) entre outros elementos possiveis de serem discutidos na relação entre a teoria da História e as realidades pesquisadas. Nesse sentido, apropriamo-nos e ressignificamos as teorias como elaboração da realidade, e não como ideias prévias operacionalizadas para produções utilitárias.

A apresentação desses pressupostos possibilita a discussão da próxima seção, que se relaciona aos cursos de extensão para a formação de professores no campo de discussão da Educação Histórica. Durante o curso de 2018, realizou-se um projeto experimental da produção de vídeos com o intuito de representar um material paradidático de professores para professores. Essa produção envolveu diferentes projetos de pesquisa e extensão, assim como a relação universidade e escola em uma perspectiva colaborativa.

\section{METODOLOGIA, REFERENCIAIS TEÓRICOS E OBJETOS DE ANÁLISE}

Entre os pressupostos apresentados anteriormente é possivel perceber elementos relacionados aos referenciais teóricos que nortearam este trabalho, assim como o curso de extensão e as produções do próprio LAPEDUH - UFPR. A presente seção coloca em diálogo esses referenciais, o processo de produção dos materiais analisados como resultados de diferentes projetos e, por fim, o material empírico que será objeto de análise.

Para estabelecer essas inter-relações é necessária uma apresentação sucinta sobre a proposta do curso de extensão realizado em parceria entre a Universidade Federal do Paraná e o Instituto Federal do Paraná no ano de 2018. 0 curso livre de extensão teve por objetivo realizar uma introdução às discussões relacionadas à teoria e à filosofia da História e suas preocupações com a didática da História. Entre as referências principais que foram discutidas destacamos o teórico e filósofo da história Jörn Rüsen le conceitos fundamentais como consciência histórica, narrativa, cultura histórica e formação), além de situar a interpretação da contribuição rüseniana segundo as interpretações relacionadas à perspectiva da aula histórica. ${ }^{7}$ Entre os interesses temáticos que foram privilegiados estão aqueles compreendidos como traumáticos (RÜSEN, 2009, 2014, 2015), difíceis (SCHWARCZ; STARLING, 2015) e sobrecarregados (BORRIES, 2011). No ano anterior (2017), o curso esteve relacionado à temática "Metodologia de Ensino-Aprendizagem e Avaliação em Temas Sociais Controversos da História".

Para a compreensão da "Aula Histórica" ver Curitiba (2016, p. 7). Trata-se do currículo de História do Ensino Fundamental (1॰ao $9^{\circ}$ ano), que contou com a assessoria da professora Maria Auxiliadora Moreira dos Santos Schmidt. Esse trabalho também é resultado das parcerias realizadas entre o LAPEDUH e a SME - Curitiba na área da formação continuada de professores. 
Em 2018 o curso esteve voltado para professoras e professores de História (dos anos finais do Ensino Fundamental e do Ensino Médio) e acadêmicos de Licenciatura em História e Pedagogia, como tem ocorrido nos últimos anos. 0 curso se caracteriza como extensão, mas, ao mesmo tempo, oferece contribuições àqueles que pretendem ingressar nesse campo por intermédio da pesquisa acadêmica.

Em 2018, um elemento novo e experimental foi realizado a partir de uma parceria entre o projeto de pesquisa "Aprendizagem Histórica e Didática da História: Teoria, Filosofia e Práxis - Possíveis Abordagens Referentes a Temas Sociais Controversos" e o projeto de extensão "Tec Vídeo", coordenado pela professora Elizabete dos Santos do Curso, o Técnico em "Produção de Áudio e Vídeo", modalidade Subsequente. 0 projeto de extensão "Tec Vídeo" tem como objetivo a divulgação de projetos realizados no Instituto Federal do Paraná (Campus Curitiba), assim como serve como estágio para os estudantes do curso que realizam as produções seguindo a forma de trabalho de uma agência de comunicação audiovisual.

A parceria resultou em três vídeos, e a ideia dessa produção partiu de um dos professores que participou do curso de extensão em 2017. De acordo com o professor Sandro Luis Fernandes, em um comentário durante o curso, era importante que o LAPEDUH investisse na produção audiovisual em virtude do alcance possível dessa forma de comunicação, sobretudo em tempos de comunicação digital.

Os vídeos foram concebidos pela equipe de estudantes do curso técnico citado, e todos os elementos audiovisuais foram pensados e determinados por eles, ou seja, os elementos técnicos (captação de imagem, de áudio, iluminação, trilha sonora), assim como roteiro, direção, produção e pós-produção. Os vídeos foram realizados entre 2018 e 2019, mas apresentam experiências realizadas pelos docentes no ano de 2017.

No presente texto a análise de conteúdo (FRANCO, 2007) e os referenciais teóricos mais característicos do campo da Didática da História formam a metodologia de análise dos vídeos citados. "[...] a emissão de mensagens está necessariamente articulada com as condições contextuais de seus produtores, condições estas que envolvem a evolução histórica, as situações econômicas e sócio culturais nas quais os emissores estão inseridos." (FRANC0, 2007, p. 19).

Esse elemento apresentado por Franco (2007) possibilita o diálogo com a forma de apreensão da realidade nas pesquisas do Laboratório, ou seja, não analisar narrativas como elementos abstratos, mas ligados às condições materiais e subjetivas de sua produção. Como debatido por (FRANCO, 2007, p. 25-26), há duas questões que devem ser levadas em consideração na análise de conteúdo: a) o produtor (pensando sobre quem e o porquê de determinada forma de narrar); e b) o receptor (quando se pensa nos efeitos que as mensagens podem causar). Sem nos limitarmos à ideia de emissão-recepção, ou seja, 
levando em consideração os vários espaços de circulação dos professores (suas relações de trabalho), na análise das enunciações dos professores que participaram da produção dos vídeos, foram considerados três pressupostos básicos:

1. Toda mensagem falada, escrita ou sensorial contém, potencialmente, uma grande quantidade de informações sobre o autor: suas filiações teóricas, concepções de mundo, interesses de classe, traços psicológicos, representantes sociais, motivações, expectativas, etc.

2. 0 produtor/autor é antes de tudo um selecionador e essa seleção não é arbitrária. Da multiplicidade de manifestações da vida humana, seleciona o que considera mais importante para "dar o seu recado" e as interpreta de acordo com seu quadro de referência. Obviamente, essa seleção é preconcebida. Sendo o produtor, ele próprio, um produto social, está condicionado pelos interesses de sua época, ou da classe a que pertence. E, principalmente, ele é formado no espírito de uma teoria da qual passa a ser o expositor. Teoria que não significa "saber erudito" e nem se contrapõe ao "saber popular", mas que transforma seus divulgadores muito mais em executores de determinadas concepções de que de seus próprios senhores.

3. A "teoria" da qual o autor é o expositor orienta sua concepção da realidade. Tal concepção (consciente ou ideologizada) é filtrada mediante seu discurso e resulta em implicações extremamente importantes, para quem se propõe fazer análise de conteúdo. (FRANCO, 2007, p. 26).

A análise de conteúdo dos vídeos levou em conta os aspectos discutidos anteriormente, assim como possibilitou perceber ideias recorrentes nas falas dos docentes. A recorrência de ideias permitiu elaborar uma proposta de categorização dos dados identificados. A identificação das ideias recorrentes foi possível a partir do momento de pós-produção com análises mais detalhadas e pela possibilidade de assistir várias vezes a cada uma das produções. Nas análises de conteúdo é possivel realizar uma primeira leitura flutuante do material a ser analisado (elementos que foram possiveis de ser realizados desde o momento da gravação) e outra depois, nas edições e testes de cada vídeo (tudo isso foi realizado como pré-análise). Após recebermos da equipe de produção os vídeos finalizados, foi possível realizar a classificação e categorização de ideias que estão relacionadas aos referenciais teóricos debatidos ao longo do curso de extensão.

A partir disso, elaboramos quadros que agrupam elementos presentes nas falas dos historiadores docentes ao longo dos vídeos e que podem ser observados a partir da relação teoria e práxis. Ressaltamos que, apesar de professores envolvidos no curso de extensão terem participado dos momentos de gravação, não ocorreu nenhum tipo de elaboração prévia das enunciações dos docentes, elemento que foi uma escolha dos aspectos técnicos do Curso de Produção de áudio e vídeo. 
Uma vez que os vídeos estão disponíveis na rede mundial de computadores a partir do canal no YouTube ${ }^{8}$ do Laboratório e os leitores poderão ter acesso direto aos materiais analisados, optamos por não transcrever as falas dos docentes, mas discutir os elementos recorrentes na relação entre teoria e práxis. Cabe, ainda, dizer que a análise do conteúdo dos vídeos não foi realizada no intuito de valorar ou hierarquizar as experiências relatadas. A análise realizada levou em consideração todos os pressupostos discutidos anteriormente e buscou destacar aspectos da relação entre teoria e práxis, os quais buscamos destacar nas enunciações analisadas. As relações com o referencial da teoria da história serão debatidas na próxima seção.

Até o momento foram produzidos três vídeos que estão disponíveis na página citada, mas por questões relacionadas às possibilidades de análise nessa produção textual, assim como para dar representatividade às diferentes redes de ensino (estadual e municipal), faremos a análise de dois vídeos, o da professora Jucilmara Luiza Loos Vieira (SEED - PR) e o do professor Sandro Luis Fernandes (SME - Curitiba).

\section{DESENUOLUIMENTO - ANÁLISE DOS UÍDEOS E ALGUMAS POSSIBILIDADES DE DIÁLOGOS COM A TEORIA A PARTIR DA PRÁXIS DE HISTORIADORES DOCENTES}

A partir das análises realizadas com base nos conteúdos dos vídeos foi possível identificar algumas ideias que são recorrentes nas enunciações dos docentes. Os elementos que serão apresentados configuram relações entre aspectos teóricos que apareceram nos cursos de formação continuada (2017 e 2018) e a incorporação desses elementos nas experiências realizadas pelos docentes em suas aulas de história (2017) com estudantes do Ensino Fundamental e Médio.

Os elementos recorrentes foram: conteúdos substantivos ou temas da história, levantamento de conhecimentos prévios, ideias históricas prévias (ou protonorrativas); o uso das fontes (como metodologia ou estratégia didática); a variedade de fontes históricas; a narrativa histórica como materialidade do pensamento ou da consciência dos estudantes; o envolvimento e superação do espaço da sala de aula como elemento de sentido da aprendizagem; e, por fim, as dificuldades que são encontradas nas relações com a escola ou com as condições de trabalho. Além desses elementos, existem outros que são possíveis de analisar nos vídeos, tanto elementos que se repetem nas três produções quanto outras

Para assistir aos vídeos, ver: Teaser... (2019). 
ideias que aparecem de maneira isolada nas falas dos docentes. Apresentaremos a seguir algumas dessas ideias relacionadas a elementos teóricos e metodológicos do campo da Educação Histórica.

Quadro 1 - Conteúdos substantivos ou temas da história

\begin{tabular}{|l|l|}
\hline Jucilmara Luiza Loos Vieira & Sandro Luis Fernandes \\
\hline - Holocausto no Ceará (1932 - seca) & - Formação do Brasil \\
- Holocausto na Alemanha & - Imigração \\
\hline
\end{tabular}

Fonte: $\mathrm{o}$ autor.

É possível perceber nas enunciações dos historiadores docentes a recorrência de elementos que fazem parte das propostas teóricas características da Educação Histórica de Portugal e da Inglaterra, por exemplo, na divisão entre os chamados conceitos substantivos e conceitos de segunda ordem. ${ }^{9}$ Característica bastante difundida entre os professores que trabalham com as propostas da Educação Histórica.

Os conceitos "de segunda ordem", também designados conceitos estruturais ou meta-históricos, exprimem noções ligadas a natureza do conhecimento histórico, tais como compreensão empática, explicação, evidência, significância, mudança em História. Os conceitos "substantivos" referem-se a noç̃̃es ligadas aos conteúdos históricos, como monarquia, democracia, feudalismo, revolução industrial, Renascimento, descobrimentos. (BARCA, 2011, p. 25).

Outro elemento recorrente nas enunciações presentes nos vídeos e que também se relaciona aos campos teóricos citados são as estratégias utilizadas nas aulas que se relacionam ao levantamento das ideias históricas prévias dos estudantes. 0 que não é algo que se limita ao campo da Educação Histórica, mas aparece em diferentes produções.

9 Para saber mais sobre essa divisão e sobre as influências teóricas que configuraram essa característica, ver o capítulo 4 da tese A Formação Histórica (Bildung) como Princípio da Didática da História no Ensino Médio: teoria e práxis, ou especificamente Oliveira (2017 p. 249). 
Quadro 2 - ldeias históricas prévias

\begin{tabular}{|l|l|}
\hline Jucilmara Luiza Loos Vieira & Sandro Luis Fernandes \\
\hline - História pouco conhecida & \\
- Quase 500.000 mortos & - Carências dos alunos \\
- Ao passo que o holocausto do nazismo todos já & - Percepção da falta de identidade e pertencimento \\
estudaram, muitos conhecem & - Dificuldades dos alunos de se sentirem parte, de se \\
- As imagens brasileiras foram associadas ao campo & reconhecerem \\
de concentração de Auschwitz & \\
\hline
\end{tabular}

Fonte: o autor.

Se recuperarmos rapidamente as discussões do campo da Educação Histórica, será possível perceber que na proposta da aula-oficina (BARCA, 2004) e na Unidade Temática Investigativa (FERNANDES, 2008), o levantamento das ideias históricas prévias já aparecia na bibliografia e passou a ser incorporado por professoras e professores. Na proposta metodológica das aulas com a fonte canção, Azambuja (2013) ressaltou que a própria teoria da consciência histórica possui fundamentação epistemológica para tratar de maneira teórico-metodológica a relação entre cultura e consciência histórica, nesse caso foi utilizando o conceito protonarrativa discutido por Rüsen (1994).

De maneira colaborativa e na relação com historiadores docentes, desde a pesquisa realizada no Município de Araucária (OLIVEIRA, 2012), vínhamos percebendo e discutindo possibilidades de compreender a aprendizagem histórica na perspectiva da práxis. Elemento que foi percebido nas enunciações dos professores entrevistados em 2011 e que foi discutido teoricamente a partir de uma aproximação entre as ideias de Paulo Freire a respeito do "universo temático do povo" ou o conjunto de seus "temas geradores" (FREIRE, 1987, p. 11, 87) e o conceito protonarrativa (ou semióforas), bem como a partir da potencialidade da relação entre as consciências históricas dos estudantes e o contexto amplo da cultura histórica (OLIVEIRA, 2012, p. 153-154). Depois do acúmulo com as pesquisas em Araucária e outras pesquisas realizadas nos últimos anos, principalmente a partir das pesquisas em colaboração com os historiadores docentes (é importante ressaltar), passamos a debater a centralidade da práxis para pensar a formação histórica (e a própria didática da história). A práxis pode ser pensada como princípio e fim da didática da história (OLIVEIRA, 2017, p. 30-37).

É possível perceber que esses aspectos teóricos dialogam com os pressupostos da formação continuada no campo da Educação Histórica discutidos anteriormente la atividade docente como trabalho; a metodologia da pesquisa colaborativa; e a compreensão da teoria da consciência histórica na perspectiva da práxis). Recuperamos esses pressupostos porque ao partir da compreensão da importância da relação da teoria com a práxis, e pensando a teoria como elaboração da realidade, é possível voltar aos vídeos e identificar nas enunciações dos professores esses elementos, ainda que não estejam organizados conforme a discussão 
teórica aqui elaborada. 0 próprio processo dessa elaboração é resultado de discussões, pesquisas e debates com os professores. É possivel notar essas perspectivas na maneira como os professores narram suas relações com o meio em que estão inseridos e na maneira pela qual pensam e elaboram suas aulas.

Com relação às aulas e como elas são encaminhadas, foi possível perceber outros elementos que são resultados das relações com a teoria, assim como da experiência dos docentes, e também foram elementos recorrentes nos conteúdos dos vídeos:

Quadro 3 - Utilização e diversidade de fontes em sala de aula (metodologias e estratégias)

\begin{tabular}{|c|c|}
\hline Jucilmara Luiza Loos Vieira & Sandro Luis Fernandes \\
\hline Análise e interpretação & Pesquisa de história de vida \\
\hline \multirow[t]{2}{*}{ Seleção pela professora } & Genealogia \\
\hline & Pesquisa com familiares \\
\hline Fotografia & Documentos pessoais \\
\hline Livro & Fotografias - industrialização/mudanças no bairro \\
\hline Video da internet & Genealogia (página ligada à comunidade religiosa) \\
\hline Iconografia pictórica & História oral (entrevista com familiares). \\
\hline
\end{tabular}

Fonte: o autor.

A utilização de fontes históricas em sala de aula não é uma prerrogativa dos debates da educação histórica, de acordo com Schmidt (2004) e Caimi (2008); pelo menos desde o início do século XX é possível perceber reivindicações no sentido de atualizações relacionadas à forma de ensinar história nas escolas no Brasil. Se nos voltarmos à obra de Droysen (2009) como uma das principais influências do pensamento de Jörn Rüsen, será possível perceber que a pesquisa como parte da atividade dos professores de história que se ocupam da educação dos jovens já estava presente no período da própria constituição do método científico da história no século XIX.10 No entanto, entre as conclusões dos textos brasileiros, como a permanência desse debate em produções científicas do campo do ensino de história, ou mesmo documentações que orientam e dão parâmetros para tal atividade são indicativos das dificuldades dessa inserção na práxis.

Nos cursos de formação continuada discutidos neste artigo, assim como em muitas produções do campo da educação histórica, tem-se insistido não apenas na necessidade da utilização de elementos do método da pesquisa histórica, mas, sobretudo, na relação entre práxis e ciência especializada. Talvez aqui esteja um elemento em que a discussão sobre o

10 Ver, por exemplo, os parágrafos 21 e 92 la respeito da relação com os vestígios do passado e da pesquisa na atividade do professor de história). 
método da história tenha constituído sentido para as relações de ensinar e aprender história entre os historiadores docentes. As matrizes do pensamento histórico debatidas por Rüsen (2015), assim como as propostas de adaptação para a Didática da História (RÜSEN, 2016) e, no caso do curso de extensão aqui discutido, a matriz da Aula Histórica (CURITIBA, 2016) são indicativos de que os historiadores docentes têm aderido a essa perspectiva de trabalho.

Tanto como metodologia de análise, crítica e interpretação das fontes quanto nas estratégias didáticas para o encaminhamento de momentos das aulas (pesquisa com familiares, genealogia e história oral), o método histórico aparece nas enunciações dos docentes. Importante ressaltar que não ocorre como reprodução do trabalho dos historiadores adaptado à sala de aula lo que muitas vezes é apontado como objeto de crítica - como se a proposta da educação histórica, ao se preocupar com aspectos da ciência da história, quisesse formar pequenos historiadores). Embora consideremos esta uma crítica inercial e que representa compreensão rasa da proposta, cabe aqui um diálogo com a crítica, assim como um esclarecimento: os elementos citados pelos docentes apresentam a potencialidade da intervenção do docente em realidades que não são pensadas apenas pela ciência da história (mas pelas ciências da educação em geral, assim como outros elementos de diálogo com as realidades). E o professor, como intelectual, pode fazer escolhas sobre elementos temáticos da história que podem auxiliar para uma ampliação da compreensão da realidade de si mesmo na relação consigo e com os outros. A elaboração qualitativa do pensamento na relação com o conhecimento histórico é apenas um dos fatores que fazem parte do processo formativo dos seres humanos na vida em sociedade. Formação humana é algo mais amplo e complexo, mas a disciplina de história, ao ser pensada a partir de elementos da sua ciência de referência (a didática da história como um princípio fundamental da própria ciência), tem contribuições significativas para aspectos da formação humana.

As propostas de trabalho apresentadas nos vídeos também possuem indícios de outro elemento recorrente que evidencia a relação teoria e práxis: trata-se da geração de sentido e significado do envolvimento dos estudantes no processo de aprendizagem.

Quadro 4 - Sentido e significado

\begin{tabular}{|l|l|}
\hline Jucilmara Luiza Loos Vieira & Sandro Luis Fernandes \\
\hline Pesquisa & Pesquisa em contraturno \\
Interdisciplinaridade & Envolvimento \\
Envolvimento & Produção de sentido e significado \\
Produção de sentido e significado & \\
\hline
\end{tabular}

Fonte: o autor. 
Nas enunciações dos historiadores docentes, foi recorrente o fato de que os estudantes demonstraram um tipo diferenciado de envolvimento nas atividades propostas, o que pode ser constatado tanto na leitura de uma referência bibliográfica por parte dos estudantes quanto no tempo extra ao momento das aulas (atividades em contraturno) para a realização do que foi proposto. Relatos como o pedido de auxílio para uma professora de outra matéria para a realização de uma proposta da aula de história, ou mesmo a mobilização de familiares para a realização de uma tarefa foram elementos apontados como característica de uma produção de sentido (elemento central na teoria rüseniana) e aspecto teórico debatido nos cursos de formação de professores na perspectiva da educação histórica, assim como o gosto (que se relaciona aos aspectos estéticos da aula e da relação com a história).

Outro elemento que merece destaque nas enunciações dos docentes é a utilização da narrativa como elemento de expressão da consciência histórica dos estudantes:

Quadro 5 - Narrativa

\begin{tabular}{|l|l|}
\hline Jucilmara Luiza Loos Vieira & Sandro Luis Fernandes \\
\hline Forma de cordel & Produção de narrativas com os resultados na \\
Relações com o presente (terrorismo, imigração de & pesquisa \\
haitianos, conflitos religiosos, etc.) & Transformação qualitativa \\
\hline
\end{tabular}

Fonte: o autor.

A professora Jucilmara destacou que recorreu à produção de um cordel como produção final das intervenções narradas, processo mobilizado por uma questão que solicitava a relação das diferentes fontes trabalhadas e que poderiam ser selecionadas pelos estudantes. A narrativa foi apontada com expressão do processo de aprendizagem histórica. 0 professor Sandro comentou que as narrativas foram trabalhadas em dois momentos, uma primeira correção com indicação de melhorias, até a entrega de uma versão final. Há uma variedade de discussões possíveis no âmbito da teoria da consciência histórica a respeito da narrativa (assim como outras propostas narrativistas), mas a presença desse elemento nas enunciações dos docentes representa mais um elemento da relação teoria e práxis. Cabe, ainda, apontar o aspecto da ampliação da quantidade de conteúdos relacionados e da qualidade do pensamento a respeito das fontes e das informações - a ampliação quantitativa e qualitativa da consciência histórica (RÜSEN, 2012, p. 88) - ao longo do processo formativo.

A formação histórica [...], inclui o processo e o produto, ou seja, o processo formativo e a formação. Essa díade dialética, por uma parte, corresponde a dimensão dinâmica do ensino e aprendizagem, reflexão, experiência, orientações; a outra parte, corresponde aos elementos de consolidação dos novos patamares, referenciais, afirmações dos sujeitos em relação as 
circunstâncias temporais. A dialética entre processo formativo - formação não tem início, assim como não se esgota na escola, mas a escola possui posição prevalente na contemporaneidade. (OLIVEIRA, 2017, p. 35).

As narrativas também foram apontadas como elemento em que apareceram as relações com a sociedade contemporânea, a relação com a própria práxis da vida. Como apresentamos muitos elementos considerados importantes na relação entre a teoria e a práxis, sendo a pesquisa colaborativa um dos elementos que potencializam o processo de formação continuada de professores na perspectiva da educação histórica, não poderíamos deixar de considerar também alguns limites apontados pelos docentes.

Quadro 6 - Dificuldades da escola e do tempo escolar

\begin{tabular}{|l|l|}
\hline Jucilmara Luiza Loos Vieira & Sandro Luis Fernandes \\
\hline $\begin{array}{l}\text { Tempo dedicado ao trabalho } \\
\text { Variedade de fontes que poderiam ser utilizadas }\end{array}$ & $\begin{array}{l}\text { Tempo dedicado ao trabalho } \\
\text { Relação entre conteúdos de exames de seleção } \\
\text { Elementos da cultura escolar }\end{array}$ \\
\hline
\end{tabular}

Fonte: o autor.

Os historiadores docentes apontaram que existem elementos ligados às características indicadas como mais tradicionais da escola, daquilo que se entende na cultura escolar sobre o que é uma aula de história, por exemplo, da utilização do livro didático e da sequência de conteúdos que muitas vezes foram apontados, seja por estudantes seja por colegas de trabalho. Elementos semelhantes também foram indicados por docentes da pesquisa realizada em 2012 no Município de Araucária. Além disso, questões relacionadas a condições de trabalho, número de alunos por turma, falta de laboratório de informática e falta de acesso a rede mundial de computadores também foram frequentes lainda que alguns desses elementos tenham sido cortados durante a edição dos vídeos pela equipe do projeto TEC-Vídeo).

Esses elementos se relacionam com o pressuposto das condições materiais objetivas das relações de trabalho e configuram objeto de preocupação nos espaços de formação continuada. As propostas, muitas vezes, são negociadas na perspectiva da pesquisa colaborativa justamente por questões relacionadas aos limites e possibilidades dos trabalhos. Destacamos, ainda, a dedicação ao trabalho e mesmo a participação nos cursos quando levamos em consideração esses elementos e, principalmente, a falta de reconhecimento do trabalho no magistério quando professores e professoras não possuem nem os planos de carreira respeitados pelo poder público. 


\section{CONSIDERAÇÕES FINAIS}

Na pesquisa publicada por Gevaerd (2019) foram apontados elementos das discussões do campo da educação histórica que foram incorporados por professores que participaram dos cursos de formação citados neste artigo. A incorporação do levantamento de carências de orientação como estratégia para o desenvolvimento das aulas foi apontada como a principal característica. Nesse caso, os objetos empíricos analisados foram os resumos apresentados em Seminários de Educação Histórica organizados pela Secretaria Municipal da Educação de Curitiba em parceria com o Laboratório de Pesquisa em Educação Histórica, em 2016 e 2017.

As análises correspondem a um número de trabalhos maior do que o do presente artigo, no entanto as possibilidades de análise a partir do resumo apresentam menos aprofundamento e percepção da incorporação do que em narrativas mais longas, como a explicação detalhada do processo de desenvolvimento das aulas, caso relacionado aos vídeos analisados neste texto. Consideramos que as análises são complementares, pois na pesquisa de Gevaerd (2019) há uma quantia mais expressiva da apropriação de um número menor de elementos da relação teoria e práxis. Nesse sentido, consideramos interessante a continuidade das produções dos vídeos, assim como das análises quantitativas dessas relações de incorporação.

Destacamos, ainda, que tanto a participação voluntária nas produções dos vídeos quanto a participação em eventos científicos e publicações realizadas pelos professores em revista de divulgação científica (VIEIRA, 2016; FERNANDES; SCHMIDT, 2019) representam outros exemplos concretos do exercício da intelectualidade, assim como da potencialidade da perspectiva da pesquisa colaborativa para a formação de professores no campo da educação histórica.

Procuramos realizar um exame das atividades do Laboratório, ao mesmo tempo em que refletimos a respeito de seus pressupostos. Nesse exercício, é possível apontar elementos de um campo de discussão reconhecido como educação histórica, que não é o único, mas que possui acúmulos para refletir sobre sua própria trajetória no Brasil, como resultado das discussões e interlocuções com intelectuais brasileiros e internacionais, com diferentes grupos de pesquisa e aspectos epistemológicos.

Outro elemento a ser considerado nessas trajetórias são as ampliações das atividades por meio da pesquisa e da extensão. Há críticas às universidades que remetem à falta de diálogo com a sociedade; ao contrário disso, o Laboratório constituiu-se justamente 
com a colaboração entre a academia e a escola básica. E, em tempos de ataques aos serviços públicos e, sobretudo, aos professores e professoras da área de humanas, imaginamos que esse trabalho serve como comprovação da efetividade da educação pública, socialmente referenciada e pautada em princípios humanistas, como a preocupação constante com o processo formativo dos estudantes e dos professores, ao passo que assumimos a provisoriedade dessas reflexões e nos mantemos abertos aos diálogos e à colaboração em defesa do crescimento perene da ciência e dos valores da democracia.

\section{REFERÊNCIAS}

AZAMBUJA, L. Jovens alunos e aprendizagem histórica: perspectivas a partir da canção popular. 2013. Tese (Doutorado em educação) - Universidade Federal do Paraná, Curitiba, 2013.

BARCA, I. Aula oficina: do projeto à avaliação. In: BARCA, I. Para uma educação de qualidade: atas da quarta jornada de educação histórica. Braga: Centro de Investigação e educação e Psicologia Universidade do Minho, 2004. p. 131-144.

BARCA, I. 0 papel da educação histórica no desenvolvimento social. In: CAINELLI, M.; SCHMDT, M. A. (org.). Educação histórica: teoria e pesquisa. ljui: Ed. Unijuí, 2011. p. 21-48.

BORRIES, B. Coping with burdening history. In: BJERG, H.; LENZ, C.; THORSTENSEN, E. (ed.). Historicizing the uses of the past. Scandinavian perspectives on history culture. historical consciousness and didactics of history related to world war II. Bielefeld: Verlag für Kommunikation, Kultur und soziale Praxis, 2011.

CAIMI, F. E. Fontes históricas na sala de aula: uma possibilidade de produção de conhecimento histórico escolar? Revista Anos 90, Porto Alegre, v. 15, n. 28, p. 129-150, dez. 2008.

FARIA, V. Justiça manda prefeitura retomar plano de carreira de professores suspenso em 2017. Gazeta do Povo, São Paulo, 3 set. 2019. Disponível em: https://www.gazetadopovo.com.br/parana/ justica-determina-que-prefeitura-enquadre-professores-em-plano-de-carreira/. Acesso em: 10 set. 2019

CURITIBA. Prefeitura Municipal de Curitiba. Currículo do Ensino Fundamental $-\uparrow^{\circ}$ ao $9^{\circ}$ ano. Curitiba: Secretaria Municipal da Educação, 2016. v. V.

DROYSEN, J. G. Manual de teoria da história. São Paulo: Vozes, 2009. 
FERNANDES, L. Z. A Reconstrução de aulas de história na perspectiva da Educação Histórica: da aula oficina a unidade temática investigativa. In: ENCONTRO NACIONAL DE PESQUISADORES DE ENSINO DE HISTÓRIA: METODOLOGIAS E NOVOS HORIZONTES, 8., 2008, São Paulo. Anais [...] São Paulo: Faculdade de Educação da Universidade de São Paulo, 2008.

FERNANDES, S.; SCHMIDT, M. Narrativa, história de vida e aprendizagem histórica. História Revista, Goiânia, v. 23, n. 2, p. 36-52, 2019.

FRANCO, M. L. P. B. Análise de conteúdo. 2. ed. Brasilia, DF: Liber Livro Editora, 2007.

FREIRE, Paulo. Pedagogia do Oprimido. São Paulo: Paz e Terra, 1987.

GEVAERD, R. T. F. Formação continuada de professores: relação entre os conceitos da "história difíiil" e a metodologia da "aula histórica". In: BECKER, G. et al. (org.). Temas sociais controversos e os desafios da educação histórica. Curitiba: W.A Editores. 2019. p. 144-155.

GRAMSCI, A. Os intelectuais e a organização da cultura. Rio de Janeiro: Civilização Brasileira, 1982.

IBIAPINA, I. M. L. de M. Pesquisa colaborativa: investigação, formação e produção de conhecimentos. Brasilia: Liber Livro Editora, 2008.

LABORATÓRIO DE PESQUISA EM EDUCAÇÃO HISTÓRICA - UFPR. Histórico. [Curitiba]: LAPEDUH - UFPR, [20--]. Disponivel em: https://lapeduh.wordpress.com/historico/. Acesso em: 10 set. 2019.

MARX, K.; ENGELS, F. A ideologia alemã: 1845-1846. São Paulo: Boitempo, 2007.

OLIVEIRA, A. G. P. de; OLIVEIRA, T. A. D. de. A didática da história e os trabalhos LAPEDUH: pressupostos da pesquisa de historiadores docentes. In: URBAN, A. C.; MARTINS, E. C. R.; CAINELLI, M. R. (org.). Educação histórica: ousadia e inovação em Educação e em História. 1. ed. Curitiba: W.A. Editores, 2018. p. 361-384.

OLIVEIRA, T. A. D. A formação histórica (Bildung) como princípio da didática da história no ensino médio: teoria e práxis. 2017. Tese (Doutorado em Educação) - Universidade Federal do Paraná, Curitiba, 2017.

OLIVEIRA, T. A. D. A relação ensino e aprendizagem como práxis: a educação histórica e a formação de professores. 2012. Dissertação (Mestrado em Educação) - Universidade Federal do Paraná, Curitiba, 2012.

RÜSEN, J. Aprendizagem histórica: fundamentos e paradigmas. Curitiba: W.A. Editores, 2012. 
RÜSEN, J. Como dar sentido ao passado: questões relevantes de meta-história. História da Historiografia: International Journal of Theory and History of Historiography, v. 2, n. 2, p. 163-209, 2009.

RÜSEN, J. Cultura faz sentido: orientações entre o hoje e o amanhã. Petrópolis: Vozes. 2014.

RÜSEN, J. Entrevista - Jörn Rüsen. Algumas ideias sobre a interseção da meta-história e da didática da história. Realizada por Marilia Gago. Revista de História Hoje, v. 5, n. 9, p. 159-170, 2016. Disponível em: https://rhhj.anpuh.org/RHHJ/article/view/245/163. Acesso em: 12 set. 2019.

RÜSEN, J. "żQué es la cultura histórica?: Reflexiones sobre una nueva manera de abordar la historia”. Traducão: F. Sánchez Costa e lb Schumacher. Keulen, Weimar y Wenen: Böhlau, 1994. p. 3-26. Disponível em: http://www.culturahistorica.es/ruesen/cultura_historica.pdf. Acesso em: 12 set. 2019.

RÜSEN, J. Razão histórica: teoria da história: os fundamentos da ciência histórica. Brasilia, DF: Ed. UnB, 2001.

RÜSEN, J. Reflexões sobre os fundamentos e mudança de paradigma na ciência histórica alemã-ocidental. In: NEVES, A. A. B.; GERTZ, R. E. (org.). A nova historiografia alemã. Porto Alegre: Ediurgs, 1987.

RÜSEN, J. Teoria da história: uma teoria da história como ciência. Brasília, DF: Ed. UFPR, 2015.

SCHMIDT, M. A. M. S. Articulando vozes, construindo identidades: contribuições de uma pesquisa em colaboração. Revista Contextos, estúdios de humanidades y ciências sociales, n. 13, p. 247-257, 2005.

SCHMDT, M. A. M. S. Entre a lembrança e a esperança: política e consciência histórica de jovens brasileiros. Cadernos de Pesquisa: Pensamento Educacional. Curitiba, v. 9, p. 108-124, 2014.

SCHMDT, M. A. M. S.; GARCIA, T. M. F. B. Consciência histórica e crítica em aulas de história. Fortaleza: Secretaria da Cultura do Estado do Ceará; Museu do Ceará, 2006.

SCHMIDT, M. A. M. S. História com pedagogia: a contribuição da obra de Jonathas Serrano na construção do código disciplinar da História no Brasil. Revista Brasileira de História, São Paulo, v. 24, n. 48, p. 189-211, 2004.

SCHMDT, M. A. M. S. Laboratório de pesquisa em educação histórica: uma experiência de investigação colaborativa. Revista de Educação Histórica, n. 1, jul./nov. 2012.

SCHMIDT, M. A. M. S.; URBAN, A. C. Curitiba, 29 de abril de 2015: para não esquecer. In: SCHMIDT, M. A. M. S.; URBAN, A. C. (org.). Um registro do 29 de abril de 2015: para não esquecer. 1. ed. Curitiba: W.A Editores, 2015. p. 9-14. 
SCHWARCZ, L. M.; STARLING, H. M. As sete maiores vergonhas do Brasil. Revista TRIP, São Paulo, 2 jun. 2015. Disponivel em: https://revistatrip.uol.com.br/trip/as-sete-maiores-vergonhas-do-brasil-por-lilia-schwarcz-e-heloisa-starling. Acesso em: 19 set. 2019.

TEASER - Educação histórica e temas controversos da história. [S. L.: s. n.], 25 set. 2019. 1 vídeo (2 min). Publicado pelo canal Laboratório de Pesquisa em Educação Histórica. Disponivel em: https://www. youtube.com/watch?v=TycdVpv9qcM\&list=PLp3RCDOKZA27famaoNwEshFfC9W5lweZD. Acesso em: 25 set. 2019.

URBAN, A. C.; MARTINS, E. C. R.; CAINELLI, M. R. (org.). Educação histórica: ousadia e inovação em Educação e em História. 1. ed. Curitiba: W.A. Editores, 2018

VIEIRA, J. L. L. História difícil: conceito holocausto no Brasil e história local? A produção do conhecimento a partir do relato oral e investigações. Revista de Educação Histórica, Curitiba v. 12, p. 48-65, 2016.

Endereço para correspondência: Rua João Negrão, 1285, Rebouças, Curitiba, Paraná, Brasil; thiagodivardim@gmail.com

Roteiro, Joaçaba, U. 45, p. 1-24, jan./dez. 2020 | e23162 |E-ISSN 2177-6059 
